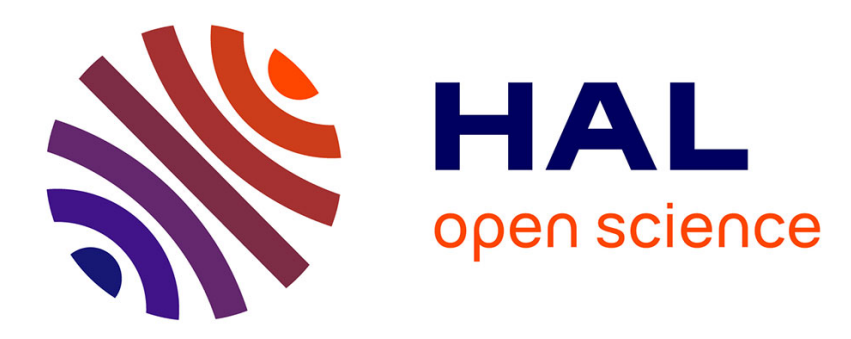

\title{
The use of large aperture accelerating tubes at high potential gradients
}

\author{
J.H. Broadhurst
}

\section{To cite this version:}

J.H. Broadhurst. The use of large aperture accelerating tubes at high potential gradients. Revue de Physique Appliquée, 1977, 12 (10), pp.1507-1509. 10.1051/rphysap:0197700120100150700 . jpa00244357

\section{HAL Id: jpa-00244357 https://hal.science/jpa-00244357}

Submitted on 1 Jan 1977

HAL is a multi-disciplinary open access archive for the deposit and dissemination of scientific research documents, whether they are published or not. The documents may come from teaching and research institutions in France or abroad, or from public or private research centers.
L'archive ouverte pluridisciplinaire HAL, est destinée au dépôt et à la diffusion de documents scientifiques de niveau recherche, publiés ou non, émanant des établissements d'enseignement et de recherche français ou étrangers, des laboratoires publics ou privés. 


\title{
THE USE OF LARGE APERTURE ACCELERATING TUBES AT HIGH POTENTIAL GRADIENTS
}

\author{
J. H. BROADHURST \\ John H. Williams Laboratory of Nuclear Physics, \\ University of Minnesota, \\ Minneapolis, Minnesota 55455, U.S.A.
}

\begin{abstract}
Résumé. - On décrit les modifications apportées en Tandem Van de Graaff MP en vue de permettre le fonctionnement pendant des périodes prolongées à des tensions supérieures à $10 \mathrm{MV}$ avec les tubes accélérateurs en aluminium.
\end{abstract}

\begin{abstract}
The changes made to an M.P. Tandem van de Graaff are described which enable the original design of aluminium accelerating tubes to be operated for an extended period at terminal potentials in excess of $10 \mathrm{MV}$.
\end{abstract}

In 1974 a set of accelerating tubes in the Minnesota M.P. Tandem van de Graaff were in need of replacement. At this time the newly developed sputter type heavy ion source had been installed and a proposal had been made to install a tritium sputter ion source in the near future. The desire to use accelerating tubes producing an accelerator acceptance phase space compatible with the emittance properties of the sputter type sources, together with the need for inexpensive accelerating tubes which could be thrown away if contaminated, led to a reexamination of the properties of the large aperture aluminium design originally supplied with the accelerator.

This design showed serious shortcomings, namely that although tests of individual accelerating tubes predicted a maximum terminal potential in excess of $12 \mathrm{MV}$ the accelerator needed extended conditioning to each $10 \mathrm{MV}$. Furthermore due to tracking of the accelerator tube insulators the accelerator performance steadily deteriorated.

In the early 1970's it was found that the loss of conditioning was considerably slowed by isolating the accelerator tubes and filling them with stripper gas at a pressure of $10^{-4}$ torr during periods of accelerator inactivity. This indicated contaminations of the surfaces either by organic material from the tube glue joints, or by mercury from the vacuum pumps; both materials being observed in a mass analysis of the residual vacuum. Before removal of the accelerating tubes the mercury diffusion pumps were therefore replaced by 1200 litre per second magnetic ion pumps and tests showed that despite the poorer base vacuum $\left(1.5 \times 10^{-7}\right.$ torr instead of $8 \times 10^{-8}$ torr previously), no detectable loss of conditioning occured after periods of fourteen days with zero terminal potential.
This supports observations made by N. Burn (1) at the Chalk River Accelerator.

The most serious problem occuring with the original accelerating tube design is the reduction in the total potential attainable by several accelerator tubes operated in series. The original design has both normal exit and entrance lenses and frequent reversal of the electrode incline direction, characteristics desirable for producing small aberrations in the accelerated beam, but allowing a considerable number of electrons to remain untraped. Measurements made by Langevin et al. [1] confirm this presence of untrapped electrons and the normal operation of the accelerator with the tube pressurized, supports their role in reducing the maximum available terminal potential.

A magnetic electron trap (Fig. 1) of sufficient moment to trap electrons of up to $4 \mathrm{MeV}$ incident energy travelling in the least favourable direction has therefore been installed in each data section between the accelerating tubes. This trap uses four diametrically magnetized ring magnets to produce the transverse magnetic field intensity pattern which results in no net angular or positional displacement of the accelerated ion beam (Fig. 2). The magnitude of the focussing moments orthogonal to the bending plane are shown in figure 3 which shows the departure from linear focussing for ions displaced from the axis. Rays transported through the magnets was analyzed and incorporated into an matrix multiplication type of analysis computer program (OPTIC) to determine the effect of aberrations. This indicated that in the phase space of a $4 \mathrm{MeV}$ proton beam would be increased by

(1) N. Burn, Chalk River National Laboratory, private communication (1974). 


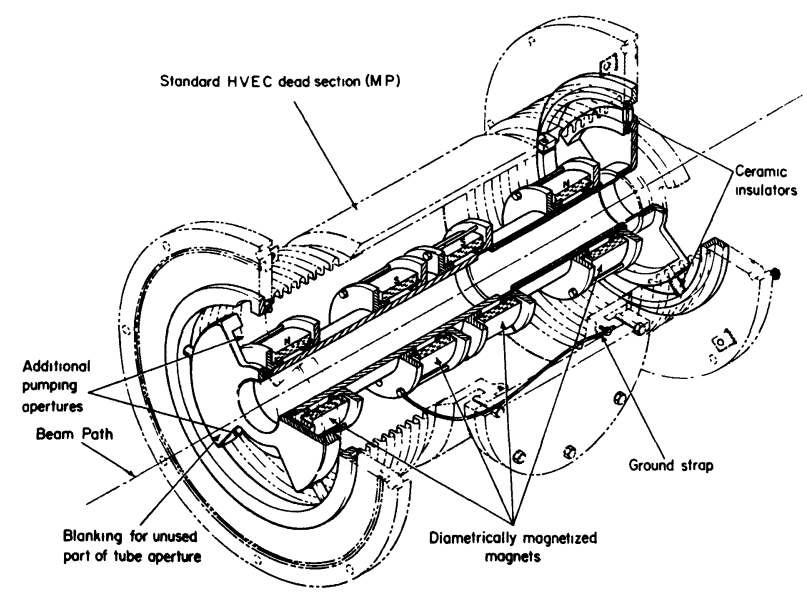

FIG. 1. - Magnetic electron trap assembly.

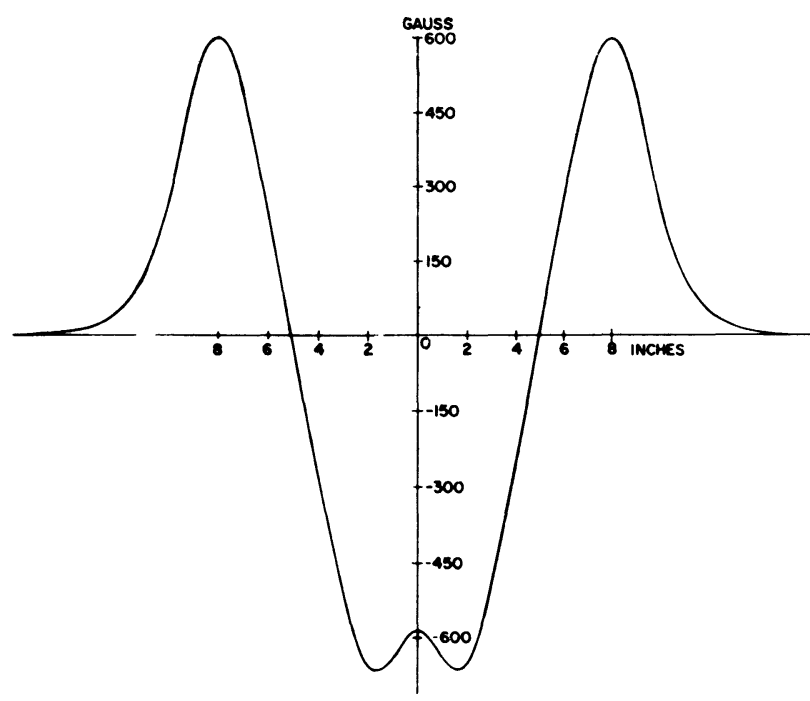

FIG. 2. - Transverse field profile.

$18 \%$ at the machine terminal. In order to avoid astigmatism in the focussing of the accelerator tube system both the strength of the trap fields were trimmed and the plane of bending of the ion beam was varied between each inter tube dead sections. In order to examine the maximum potential gradient of each accelerator tube a guiding system was installed in the accelerator to allow each tube to be individually conditioned. This is now normal operating practice, for with the absence of tank conditioning, the set of eight tubes can be conditioned by observation of vacuum indications in a period of four hours to an equivalent terminal potential of $12.2 \mathrm{MV}$.

Measurements made on a set of accelerator tubes after they had become unusable for experimentation revealed that the initiation and development of tracking (which occurred mainly during terminal sparks) was a function of tank gas pressure. As the breakdown potential of the tube spark gaps is varied by tank pressure it was deduced that tracking occurs due to breakdown of the internal gap between electrodes in preference to the spark gaps during the overvoltage
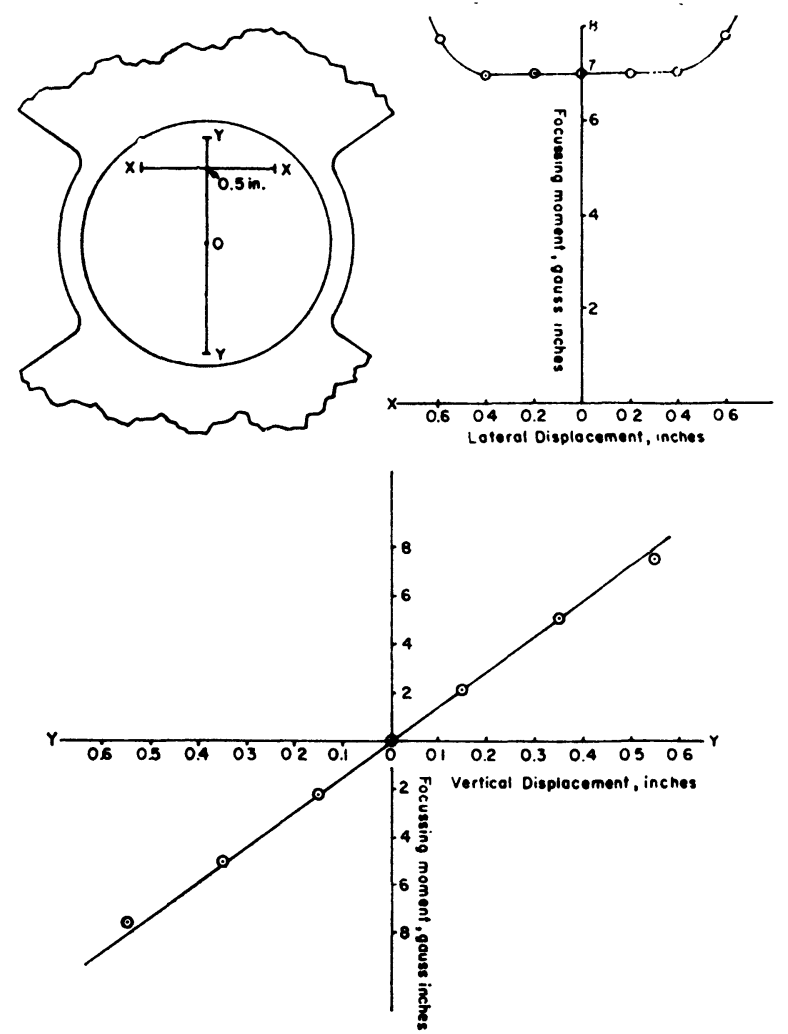

FIG. 3. - Focussing moments off axis in the electron trap.

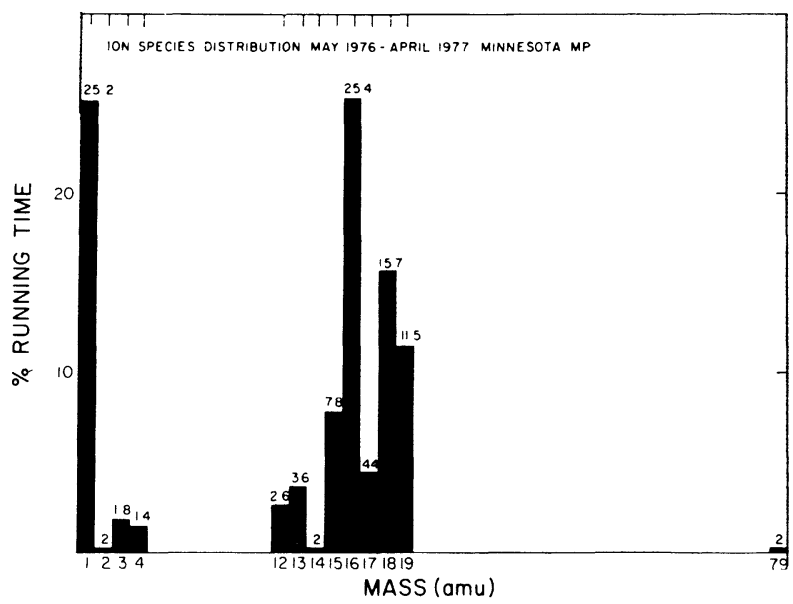

FIG. 4. - 12 Month accelerated ion species distribution.

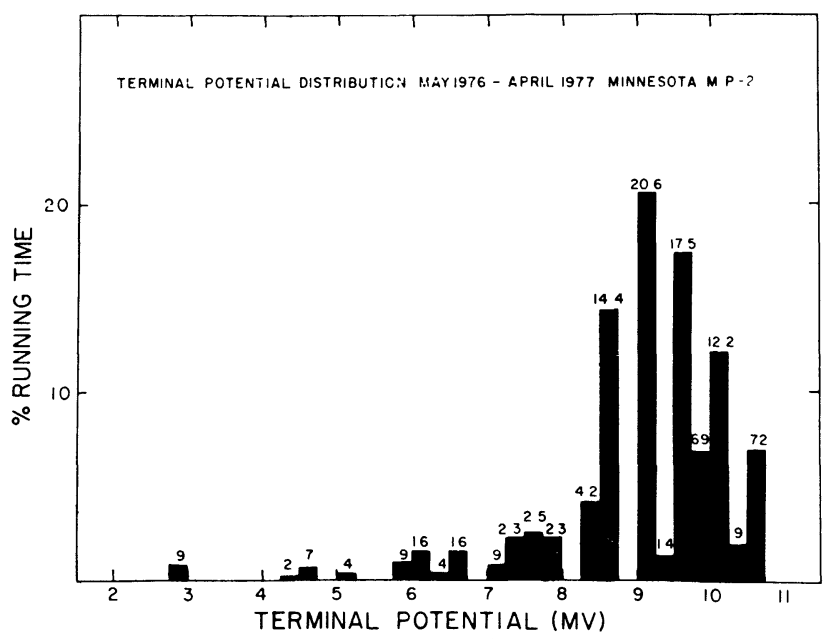

FIG. 5. - 12 Month terminal potential distribution. 
transients caused by the terminal to tank sparks. Once a discharge had started inside the tube energy would be transferred into it from the column structure. The tube electrodes have been decoupled from the column structure by connecting them through $50 \mathrm{~cm}$ long ungapped resistors of nominal value $15 \mathrm{k}$ ohms. These resistors together with the tube capacitance provides a $20 \times 10^{-6}$ second integrating time which prevented sharp overvoltage transients from being applied to the tube electrodes and prevent transfer of large amounts of energy to the tube in the event of an inter electrode discharge.

These changes have produced an accelerator which, once the tubes are conditioned to $12.2 \mathrm{MV}$ equivalent terminal potential will go directly to $10.7 \mathrm{MV}$ and can then be tank conditioned to $11.7 \mathrm{MV}$ at which point tank sparks occur without previous tube activity. Over the first 6500 hours of operation no tracks appeared on any tube section and to date (approximatley 9000 hours) three light tracks are visible on two sections of tube number four. More important perhaps is the effect of this machine performance on the experimental program of the laboratory which over the period shown in figures 4,5 had a gross beam on time of $58 \%$ at unanalyzed beam currents up to 20 electrical microamperes.

\section{References}

[1] Langevin M., Bretonneau P. and Cieur M., X-ray survey of inclined field tubes conditioning, International Conference on the Technology of Electrostatic Accelerators, Daresbury, 1973 